\title{
Assessment of the characteristics of the municipal solid waste management system based on the apparatus of the theory of reliability
}

\author{
V.E. Gvozdev, O.I. Khristodulo, O.Y. Bezhaeva, M.R. Shamsutdinov \\ o-hristodulo@mail.ru \\ Ufa State Aviation Technical University, Ufa, Russia
}

\begin{abstract}
Currently, the problem of organizing a municipal solid waste management system (MSW) has become more acute in Russian regions and all over the world. Various environmental and economic problems, as well as problems related to public health negatively affect many aspects of the development of modern society. Therefore, the careful organization of the management of the MSW management system is of great social importance and needs constant improvement.

In this paper, we look at the MSW management system from the point of various scientific approaches, namely, structural analysis methods, geoinformation technology methods, reliability theory for complex technical systems, evergetics, graph theory and fuzzy logic methods, including the apparatus of linguistic variables. The purpose of the work is to show the possibility of application and systematic combination of the above scientific methods that have proven themselves well in their fields to a new area of the MSW management systems. However, just application of these approaches is impossible without their further adaptation and systematization from the point of view of existing approaches to the management of similar systems.

As part of this study, elements of the MSW management system were identified and a topological model of the system was developed. Structural-logical models of reliability at various levels of abstraction were also built.

Key words: waste recycling, municipal solid waste, geographic information systems, evergetics, reliability theory, linguistic
\end{abstract} variables.

\section{Introduction}

These days, one of the most pressing issues, both for Russia and its entities, are problems in the field of environmental protection. Despite the fact that in recent years various environmental organizations have positively influenced the current situation, there have been no qualitative changes in improving the environmental situation. One of the most pernicious and most dangerous in terms of environmental impact problems is the irrational and unstructured waste management.

Currently, the problem of collection, removal, storage and disposal of municipal solid waste (MSW) has become more acute in most regions of Russia. On average, about $400 \mathrm{~kg}$ of waste generated per year falls on one resident of a metropolis [1]. Despite the huge numbers, the MSW management system has not undergone significant changes. The main methods of waste treatment are still landfill, incineration at specialized sites and partial processing.

The imperfect organization of the MSW management system can create a number of issues, both for different sectors of the national economy, the environment, and for the population. In particular, the accompanying problems of a poorly organized system of MSW management are the emergence of natural dumps, overflow of existing landfills for MSW storage and fatal effects on the ecosystem caused by harmful emissions into the atmosphere. All this directly affects the occurrence of serious health problems in the population due to the deterioration of the environmental situation, sanitary and hygienic living conditions of the population and the emergence of factors contributing to the formation of an unfavorable psychosocial environment for the people.

The events of recent days (the COVID-19 pandemic) have vividly indicated that when assessing alternative options for building sociotechnical systems from the standpoint of functional safety, it is necessary to assess the possible consequences of negative events, not only those that previously took place, but also those that can only happen.

The works of many researchers have been devoted to the development of methodological and theoretical foundations for the management of functional safety of subject-centric systems [2-5]. Nevertheless, theoretical foundations are required to be further developed, allowing scientifically based adaptation of developments that have proven to be effective in managing the functional safety of subject-centric systems of a different nature (health care, aviation, military operations, etc.) to be implemented to functional safety management of MSW handling systems. It seems that, as a conceptual basis for ensuring the functional safety of the MSW management system, it is advisable to choose an approach rendered in literature as "barrier thinking" [6]. Its foundation is the defense-indepth philosophy, developed as part of research related to improving the functional safety of the nuclear industry. The focus of philosophy is the development of multi-layer defense systems. Meanwhile, it is assumed that a separate barrier cannot completely prevent and eliminate the negative consequences of hazardous effects. However, the construction of a system of barriers qualitatively improves the protective properties of the system due to the system effect.

This work looks at one of the approaches to the study of the MSW management system, which can be considered as an element in the system of constructing barriers (the issue of building barriers is considered more fully, for example, in [7]). The scientific idea of the proposed approach, which is based on the theory of evergetics as the philosophical basis [8], consists in adapting the methods for analyzing the reliability of technical systems under fuzzy estimates of the reliability characteristics of elements as applied to the MSW systems [9]. 


\section{The features of the management of MSW systems}

The management of MSW in the region should begin with the organization of a unified system of production accounting for waste, which is the primary information flow [10]. The primary production waste accounting system includes internal current information and consists of a quantitative assessment of waste generation for each technological operation, both by actual indicators of MSW generation, and by material balance methods, as well as by calculation methods. An environmental assessment of the product's life cycle takes into account the impact on the environment and human health of not only the material itself, but also by the processes that accompany it throughout the life cycle: from the extraction of raw materials for its production to its destruction, disposal, or reuse for new construction products.

The MSW management system is a subject-centric complex technical system. The main elements of a MSW management system are waste sorting stations, waste recycling stations, and landfills located in a specific area. At the same time, a critical factor in the effectiveness of the MSW management system is the attitude of various target groups of subjects: the population; representatives of authorities; business representatives; scientists; public figures. This necessitates the consideration of the subjective component in the study of the MSW management systems. And finally, when studying the MSW management system, it is necessary to take into account that it is a geotechnical object, i.e. a geographically distributed system with a unique combination of natural and technogenic components throughout the territory [11-12], etc.

Hence, firstly, there are reasons to adapt approaches that are well established in other applied fields of research of complex subject-centric technical systems into the field of MSW management [13-14]. Secondly, the limited portability of the results obtained to other geotechnical systems should be considered [15-16].

The most famous metaphor representing the essence of "barrier thinking" is proposed in 1990 by the British scientist J. Reason. This model has found application in solving various problems of managing complex subjectcentric systems of different classes and is widely used in areas such as risk management for aviation, engineering, and medicine [17-18]. This metaphor suggests analyzing alternative options for constructing false systems in the early stages of their life cycle in order to reduce the number of systemic errors. In the framework of the approach defined in this paper, this suggests the adaptation of structural methods for analyzing the reliability of technical systems, taking into account the territorial features of various components of the MSW management system.

\section{Transformation of the MSW management system to a type that allows the application of reliability analysis methods based on structural logical schemes}

The results presented below were obtained in relation to the MSW management system utilized in the Republic of Bashkortostan.

The territorial waste management system is made up of waste producers such as municipal districts (MO); waste processing structures like waste sorting stations (MCC); waste recycling stations (MПC), waste landfills (П); waste collection and transportation services.

To highlight the elements of the MSW management system, the following basic principles of the analysis of territorial systems are used. These principles are the principle of logical completeness in a functional sense and the principle of transport accessibility [19].

Following the principle of logical completeness, the purpose of the MSW management system is to directly organize the collection, transportation and further processing (disposal) of waste. Consequently, the elements of the system will be waste producers, in this case of municipal districts, waste processing enterprises, here they are waste sorting stations (MCC), waste recycling stations (MПC) and waste landfills (П). These elements ensure the implementation of the goal of the MSW management system [20-21].

The nature of the relations of the elements with each other should be clarified: at the level of municipal districts, the regional operator collects the waste generated by households and enterprises, and thereby solves the logically completed task: to collect all MSW from the territory. The collected waste is sent to waste sorting stations for the separation of MSW by hazard types and classes for their further disposal at specialized waste processing enterprises or directly at landfills. There may be cases of transportation of waste for temporary storage at landfills in cases of temporary inability of the MCC and the MПC to accept MSW due to the overflow or in the case of technical or other equipment failures. Therefore, a separate functional task is the transportation of MSW, which makes it possible to distinguish the transport network as the element of the system.

Consider the MSW collection and transportation system: we will designate all waste producers of a specific municipal entity as MO, waste sorting stations as MCC, waste recycling stations as $\mathrm{M \Pi C}$, and landfills as $\Pi$. Also, we will consider the main links of the waste transportation chain: from the municipality to the landfill $(\mathrm{MO} \rightarrow \Pi)$; from the landfill to the waste sorting station $(\Pi \rightarrow \mathrm{MCC})$; from the waste sorting station to the waste recycling station $(\mathrm{MCC} \rightarrow \mathrm{M \Pi C})$.

As an example, we will consider municipalities of the Yanaul, Krasnokamsky, Kaltasinsky, Buraevsky, Tatyshlinsky and Baltachevsky municipal districts of the Republic of Bashkortostan (Fig. 1).

Let's define the conventions for the following municipalities: Yanaul (MO1), Neftekamsk (MO2), Agidel (MO3), Krasnokholmsky (MO4), Verhnie Tatyshly (MO5), Staroboltachevo (MO6), Buraevo (MO7). The proposed routes for transporting MSW from 
municipalities (MO) to waste sorting stations (MCC) are presented in Figure 2.

To highlight elements of the MSW management system, we use a functional approach.

From the point of view of functional completeness and indivisibility, the following groups of elements of the waste management system can be distinguished: $\langle\{\mathrm{MO}\},\{\mathrm{R}\},\{\mathrm{MCC}\},\{\mathrm{M \Pi}\},\{\Pi\}\rangle$.

The objects of the system are: $\{\mathrm{MO}\}$ is a set of municipalities (nodes of the graph); $\{\mathrm{R}\}$ is a set of transportation routes connecting objects (edges of the graph); $\{\mathrm{MCC}\}$ is a set of waste sorting stations (nodes of the graph); $\{\mathrm{M \Pi \Pi \}}$ is a set of waste recycling stations (nodes of the graph); $\{\Pi\}$ is a set of polygons (nodes of the graph)

We will transform the topological model of the MSW collection and transportation system to the form of a graph that reflects the various communication routes (roads) between the MO, П, and MCC (Fig. 3).

The results obtained form the basis for further use of formal methods of structural reliability analysis.

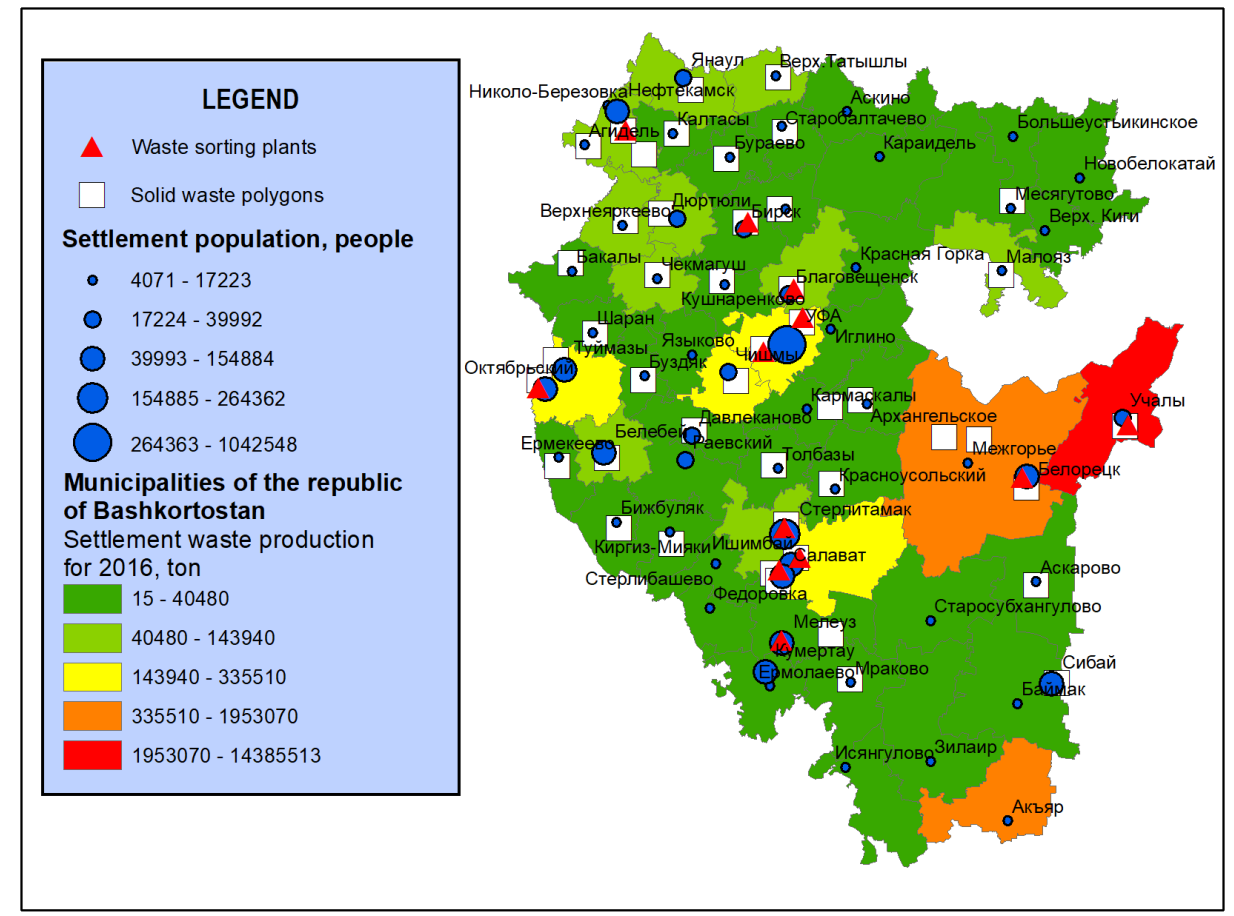

Fig. 1. Map of the location of elements of the MSW management system in the Republic of Bashkortostan

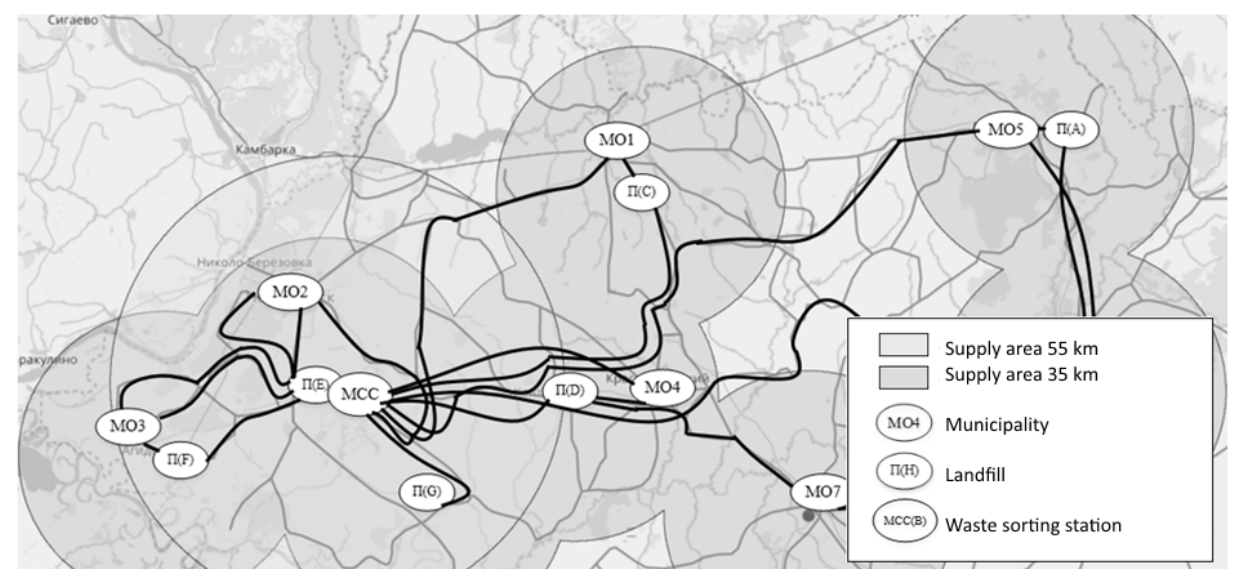

Fig. 2. A fragment of a topological model of the considered MSW collection and transportation system

\section{Structural-logical schemes of different levels of abstraction of the MSW management system}

The works on the theory of reliability for technical systems emphasize that the formulation of the concept of "failure" is the basis for building models of reliability for technical systems.
Due to the complexity of the MSW management system, as well as its multi-level structure, the definition of the element failure concept will be different for each level of the MSW management system, namely the level of the municipality, the level of the regional operator and the level of the region. Therefore, for each formulation of the concept of failure, there will be its own model of system reliability. 


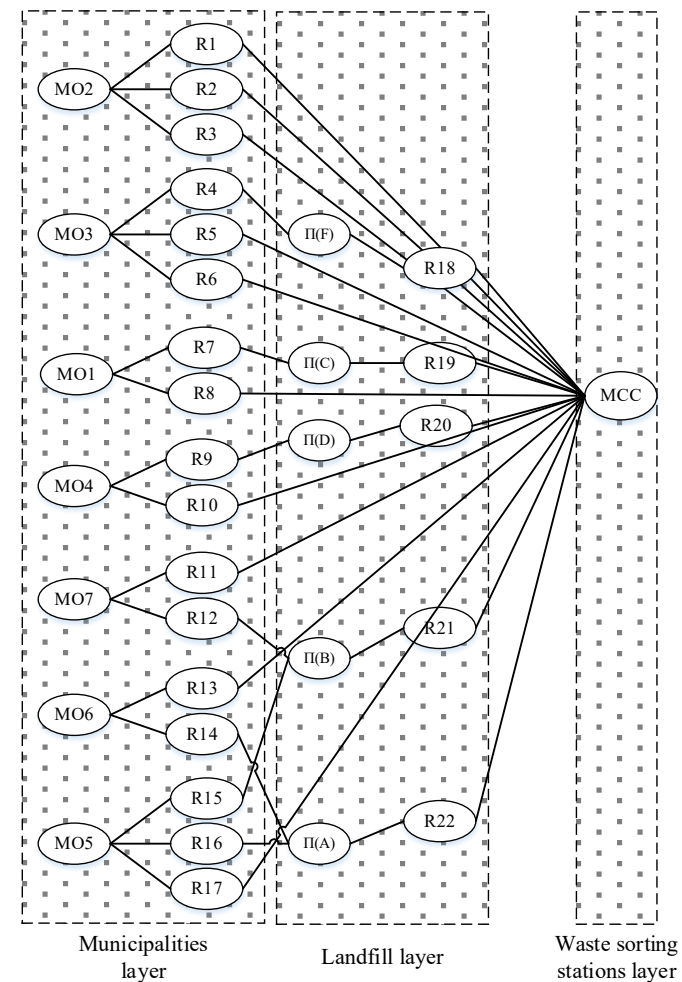

Fig. 3. Model of the network structure of the MSW collection and transportation system

\section{Structural logical model of reliability at the level of container sites}

At the level of container sites, the refusal will mean the following: 1) inability of the regional MSW management operator to organize the collection of MSW from the container sites (special sites for bulky waste, the territory adjacent to the place of garbage loading) due to reasons such as the absence of a container on the site, lack of access to the container on the site, overflow of containers installed on the site in at least for one household; 2) inability of the regional MSW management operator to collect MSW from container sites due to the absence or improper state of roads at least for one household.

At this level of abstraction, the functional elements of the system will be $\{\mathrm{MO}, \mathrm{R}\}$, where $\mathrm{MO}$ refers to a container site for collecting MSW for a municipality, and $\{R\}$ means transport routes between container sites for collecting MSW and waste sorting stations or landfills.

Based on the defined definitions, the container site may be associated with structural-logical model (Fig. 4).

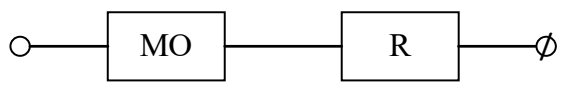

Fig. 4. Structural logical model of system reliability at the container site level

\section{Structural logical model of reliability at the level of the municipality}

In the case of many sites and several roads from container sites to waste sorting stations or landfills with the same wording of the concept of failure, the structural logical model accepts the one presented in Figure 5. This model considers the fact that before the container site $i$ $\left(\mathrm{MO}_{\mathrm{i}}\right)$ can be reached in different ways $\left\{\mathrm{R}_{\mathrm{i}, \mathrm{j}}\right\}$.

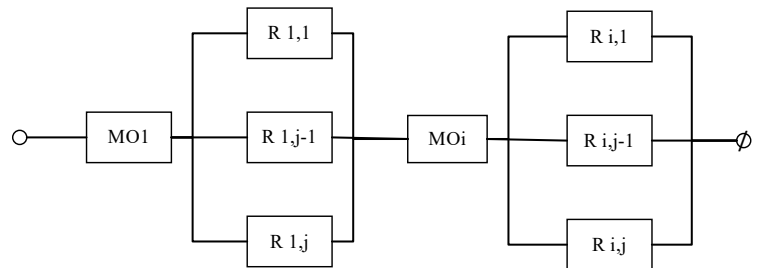

Fig. 5. Structural logical model of system reliability at the level of the municipality

\section{Qualitative assessment of reliability indicators of the components of the MSW management system}

The basis for obtaining quantitative estimates of reliability indicators based on structural logical schemes is the use of failure probabilities (fail-free operation) of the elements that make up the scheme. When analyzing the reliability of technical systems, reliability indicators are either presented in the passport data for the elements or can be obtained through specially organized tests. When analyzing MSW management systems, it is not possible to obtain reliability indicators through the above approaches. For that reason, it is proposed to use the approach described in [22] to obtain qualitative estimates of reliability. The paper describes the procedure for estimating paths in a graph for the case of the edges of the graph are weighted as values of a pre-formed linearly ordered linguistic scale (an example of a linguistic scale in relation to reliability problems can be, for example, \{unbelievable, unlikely, probably\}). Following this procedure, if a consistent connection of elements takes place in the structural logical scheme, the reliability estimate will be the smallest of the linguistic evaluations that are assigned to each element. In the case of a parallel connection, the estimate will be the largest of the estimates. Figures 6-7 show examples corresponding to serial and parallel connection of structural logic elements.

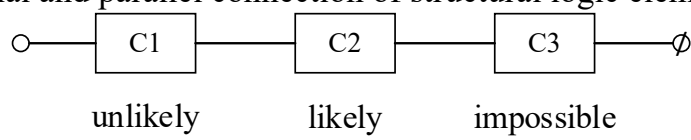

Fig. 6. Series connection of elements weighted by linguistic evaluations

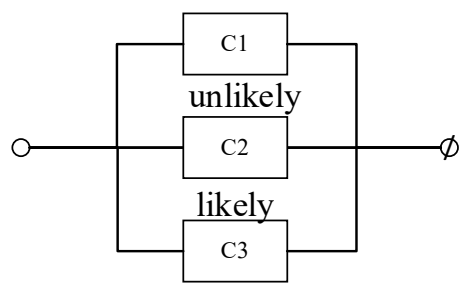

impossible

Fig. 7. Parallel connection of elements weighted by linguistic estimates

For the example in Figure 6, the final estimate would be min $\{$ unlikely, likely, impossible $\}=$ impossible. For the example in Figure 7, the final score would be max \{unlikely, likely, impossible $\}=$ likely. The use of linearly ordered linguistic variables makes it possible to obtain qualitative estimates of the reliability characteristics for models of container sites and municipalities. 


\section{Conclusions}

The proposed approach, based on a systematic combination of the geographic information technologies, the apparatus of the theory of reliability, and the apparatus of linguistic scales allows to obtain qualitative estimates of reliability of the waste management system components. This makes it possible to formalize the procedure for comparing alternative options for the location of elements of the MSW management system at the early stages of designing geotechnical systems. The proposed approach is one of the practical methods for implementing barrier thinking in a as socially significant area as waste management.

\section{Acknowledgments}

The reported study was funded by RFBR, project number 18-08-00885.

\section{References:}

[1] Kosolapov N. A. Statistics on MSW in Russia // Scientific and Methodological Electronic Journal "Concept". 2014.Vol. 26.S. 581-585.

[2] G. Druzhinin. Reliability of automated systems. Ed. 3rd, rev. and add. M., "Energy", 1977. 536 p.

[3] Parkinson D.B. Parameter Design in System Reliability // Quality Technology \& Quantitative Management, Volume 3, 2006 - Issue 1, pp. 93-102, DOI: 10.1080 / 16843703.2006.11673102

[4] Lin Y.-K., Kuo P.-H., Chang C.-C. System reliability for joint minimal paths under time constraint // Journal of the Chinese Institute of Engineers, Volume 37, 2014 - Issue 1, pp. 110-121, DOI: 10.1080 / 02533839.2012 .747250

[5] Chavaillaz A., Sauer J. Operator adaptation to changes in system reliability under adaptable automation // Ergonomics, Volume 60, 2017 - Issue 9, pp. 1261-1272, DOI: 10.1080 00140139.2016.1261187

[6] BowTieXP. The next generation BowTie methodology tool. BowTie Methodology Manual. Revision 15. (Mar 27, 2015). 64 p.

[7] TRIPOD BETA. Guidance on using Tripod Beta in the investigation and analysis of incidents, accidents and business losses. February 2015. Version 5.01. 92 p.

[8] Wittich V.A. Inhomogeneous actor and everyday life as the key concepts of evergetics: preprint - Samara: Federal State Budgetary Institution of Science Institute for Problems of Management of Complex Systems of the Russian Academy of Sciences, 2014. $12 \mathrm{p}$.

[9] Rastrigin L. A. Adaptation of complex systems. Riga: Zinatne, 1981. 375 p.

[10] Tskhovrebov E.S., Velichko E.G. Scientific and methodological approaches to creating a model of an integrated system for managing the flow of construction waste // Vestnik MGSU. 2015. No 9. P. 95-110

[11] Reimers N.F. Nature management. Dictionary. M.: Thought, $1990.637 \mathrm{~s}$
[12] Mikhailov N.I. Physical and geographical zoning. M $\therefore$ Publishing house of Moscow State University, 1985.

[13] Shcherbatov I.A., Protalinsky O.M. Complex, poorly formalized multicomponent technical systems // Management of large systems: proceedings. 2013. No. 45. S. 30-46.

[14]Kuj S.A. The multidimensional nature of the consideration of complex systems // Prospects for science and education. 2014. No. 1 (7). S. 38-43.

[15] Miroshnik IV, Nikiforov V.O., Fradkov A.L. Nonlinear and adaptive control of complex dynamic systems. St. Petersburg: Nauka, 2000.549 s.

[16] Synergetic management methods for complex systems / A. A. Kolesnikov [et al.]; under the general. ed. A.A. Kolesnikova. M .: URSS, $2006.300 \mathrm{~s}$.

[17] Reason J. Human error: models and management. BMJ. 2000; 320: 768-70. DOI: $10.1136 /$ bmj.320.7237.768.

[18]Reason J. Managing the Risks of Organizational Accidents. Aldershot, UK: Ashgate; 1997.

[19] Velmozhin A. V. Theory of transport processes and systems: a textbook for high schools / A. V. Velmozhin, V. A. Gudkov, L. B. Mirotin. M .: Transport, 1998.167 s.

[20] Gvozdev V.E., Khristodulo O.I. Information support for decision making in waste management tasks based on mathematical-geoinformation modeling // Information Technologies. 2019.Vol. 25. No. 8. P. 482-489.

[21] Gvozdev V.E., Khristodulo O.I., Sazonova T.V., Fakhretdinova E.B. The use of technologies of geographic information and mathematical modeling to assess the validity of the choice of location of waste processing enterprises // Auditorium. 2018. No. 3 (19). S. 63-72.

[22] C. Enrique Pelaz, John B. Bowles. Using Fuzzy Cognitive Maps as a System Model for Failure Modes and Effects Analysis // INFORMATION SCIENCES 88, 177-199 (1996).

\section{About the authors}

Olga I. Khristodulo, Doctor of Technical Sciences, Professor, Department of Geoinformation Systems, Ufa State Aviation Technical University. E-mail: o-hristodulo@mail.ru.

Vladimir E. Gvozdev, Doctor of Technical Sciences, Professor, Department of Technical Cybernetics, Ufa State Aviation Technical University. E-mail: wega55@mail.ru.

Oxana Y. Bezhaeva, assistant professor of Technical Sciences, Professor, Department of Technical Cybernetics, Ufa State Aviation Technical University. E-mail: obezhaeva@gmail.com.

Marat R. Shamsutdinov, PhD student, Department of Geographic Information Systems, Ufa State Aviation Technical University. E-mail: tsham@rambler.ru. 